\title{
Calprotectin strongly and independently predicts relapse in rheumatoid arthritis and polyarticular psoriatic arthritis patients treated with tumor necrosis factor inhibitors: a 1-year prospective cohort study
}

José Inciarte-Mundo', Julio Ramirez', Maria Victoria Hernández', Virginia Ruiz-Esquide1, Andrea Cuervo', Sonia Raquel Cabrera-Villalba', Mariona Pascal ${ }^{2}$, Jordi Yagüe ${ }^{2}$, Juan D. Cañete ${ }^{1}$ and Raimon Sanmarti ${ }^{*}$

\begin{abstract}
Background: Calprotectin is a biomarker of disease activity in rheumatoid arthritis (RA) and psoriatic arthritis (PsA) and predicts relapse in juvenile idiopathic arthritis. Higher drug trough serum levels are associated with a good response in patients treated with tumor necrosis factor inhibitors (TNFi). Power Doppler ultrasound synovitis is predictive of relapse and structural damage progression in patients in clinical remission. The purpose of this study was to analyze the accuracy of serum calprotectin levels, drug trough serum levels (TSL), and power Doppler (PD) activity as predictors of relapse in RA and PSA patients in remission or with low disease activity receiving TNFi.

Methods: This was a longitudinal, prospective, 1-year single-center study of 103 patients (47 RA, 56 PsA) receiving TNFi in remission or with low disease activity (28-joint Disease Activity Score (DAS28) $\leq 3.2$ ). The predictive value of serum calprotectin, TNFi TSL, and PD were assessed using receiver operating characteristic (ROC) analyses. To illustrate the predictive performance of calprotectin, TNFi TSL, and PD score, Kaplan-Meier curves were constructed from baseline to relapse. Associations between baseline factors and relapse were determined using Cox regression models. Multivariate models were constructed to analyze the effect of covariates and to fully adjust the association between calprotectin, TNFi TSL, and PD score with relapse. A generalized estimating equation model with an identity link for longitudinal continuous outcomes was used to assess the effect of covariates on TNFi TSL.
\end{abstract}

(Continued on next page)

\footnotetext{
*Correspondence: sanmarti@clinic.cat

'Department of Rheumatology, Hospital Clinic, University of Barcelona, Carrer

Villarroel 170, 08036 Barcelona, Spain

Full list of author information is available at the end of the article
}

(c) The Author(s). 2018 Open Access This article is distributed under the terms of the Creative Commons Attribution 4.0 International License (http://creativecommons.org/licenses/by/4.0/), which permits unrestricted use, distribution, and reproduction in any medium, provided you give appropriate credit to the original author(s) and the source, provide a link to the Creative Commons license, and indicate if changes were made. The Creative Commons Public Domain Dedication waiver (http://creativecommons.org/publicdomain/zero/1.0/) applies to the data made available in this article, unless otherwise stated. 
(Continued from previous page)

Results: Ninety-five patients completed 1 year of follow-up, of whom 12 experienced a relapse. At baseline, relapsers had higher calprotectin levels, lower TNFi TSL, and higher PD activity than nonrelapsers. ROC analysis showed calprotectin fully predicted relapse (area under the curve (AUC) $=1.00$ ). TNFi TSL and PD had an AUC of 0.790 (95\% confidence interval (Cl) 0.691-0.889) and 0.877 (95\% Cl 0.772-0.981), respectively. Survival analyses and log rank tests showed significant differences between groups according to calprotectin serum levels $(p<0.001)$, TNFi TSL $(p=0.004)$, and PD score $(p<0.001)$. Univariate Cox regression models showed that time-to-remission/low disease activity (hazard ratio $(H R)=1.17, p<0.001)$, calprotectin levels $(H R=2.38, p<0.001), T N F i$ TSL $(H R=0.47$, $p=0.018)$, and PD score $(H R=1.31, p<0.001)$ were significantly associated with disease relapse. In the multivariate analysis, only baseline calprotectin levels independently predicted disease relapse $(H R=2.41, p=0.002)$. The generalized estimating equation analysis showed that only disease activity by DAS28-erythrocyte sedimentation rate (ESR) was significantly associated with longitudinal changes in TNFi TSL (regression coefficient 0.26 (0.0676 to 0.0036), $p=0.001$ ).

Conclusion: Time-to-remission/low disease activity, calprotectin serum levels, TNFi TSL, and PD score were significantly associated with disease relapse. However, only baseline calprotectin serum levels independently predicted disease relapse in RA and PSA patients under TNFi therapy.

Keywords: Calprotectin, TNFi serum trough levels, Ultrasound, Relapse, Biomarkers, Predictors, Rheumatoid arthritis, Psoriatic arthritis

\section{Background}

Biological therapies have dramatically improved the management and prognosis of rheumatoid arthritis (RA) and psoriatic arthritis (PsA). Remission or low disease activity is possible in an increasing number of patients. Nevertheless, persistent remission is more difficult to achieve since disease relapses are common. In patients classified as in clinical remission, low-grade inflammatory activity may persist but remain undetectable by routine tests. Subclinical disease activity may result in disease relapse. Musculoskeletal ultrasound (MSUS) has shown that a significant proportion of patients classified as in remission exhibit a power Doppler (PD) signal [1] which is associated with short-term relapse in RA patients [2, 3].

Calprotectin, a member of the S100 protein family, is an important proinflammatory factor of innate immunity, acting as an endogenous damage-associated molecular pattern molecule via Toll-like receptor 4 activation. Higher calprotectin levels have been found in serum from RA and PsA patients [4, 5]. Calprotectin serum levels correlate with disease activity and are independently associated with radiographic progression in RA [6, 7]. Moreover, calprotectin levels predict the response to biologic therapy in RA and PsA patients $[8,9]$. Our research group has demonstrated that serum calprotectin stratifies disease activity more accurately than C-reactive protein (CRP) or the erythrocyte sedimentation rate (ESR) in patients receiving tumor necrosis factor inhibitors (TNFi) [10] or tocilizumab [11], and strongly correlates with power Doppler ultrasound synovitis (PDUS) in RA and PsA patients with low disease activity [12]. In other rheumatic diseases, such as juvenile idiopathic arthritis, calprotectin more accurately predicted relapse in patients in remission [13]; therefore, calprotectin might be useful in predicting relapse in RA and PsA patients with low disease activity.

Recent studies have found a significant dose-response relationship between the extent of clinical improvement and TNFi trough serum levels in RA and spondyloarthritis (SpA) patients [14, 15]. Higher TNFi trough serum levels have been associated with good therapeutic responses [16].Therefore, patients with low TNFi trough serum levels might be more prone to relapse.

The aim of this study was to determine the accuracy of baseline calprotectin, TNFi trough serum levels, and power Doppler (PD) score in predicting disease relapse in RA and PsA patients in remission or with low disease activity. In addition, we examined other baseline factors related to relapse, the performance of calprotectin and TNFi trough serum levels during relapse, and factors associated with longitudinal changes in TNFi trough serum levels.

\section{Patients and methods}

This longitudinal prospective observational single-center study included 103 consecutive RA patients (according to American College of Rheumatology (ACR) 1987 criteria) and polyarticular PsA patients (according to the Classification of Psoriatic Arthritis (CASPAR)) from our Arthritis Unit. Patients were enrolled between March 2013 and September 2014, with follow-up ending in September 2015. All patients were in remission (28-joint Disease Activity Score (DAS28)-ESR $\leq 2.6$ ) or had low disease activity (DAS28-ESR $\leq 3.2)$ in two consecutive visits at least 3 months apart and were currently receiving adalimumab (ADA), etanercept (ETN), or infliximab (IFX). Exclusion criteria included patients with higher 
levels of disease activity (DAS28 $>3.2$ ) or PsA patients with axial or entheseal involvement, or an oligoarticular peripheral pattern. Details on demographic data, disease duration, autoantibody status, radiological data, concomitant conventional synthetic disease-modifying antirheumatic drug (csDMARD) therapy, and dose and duration of biological therapy were collected. Some patients received a reduced dose of biologic therapy due to persistent remission/low disease activity. A reduced dose was defined as treatment with a lower amount of the drug or longer intervals of administration than recommended in each product package insert.

\section{Definition of disease relapse}

A disease relapse was defined using the revised European League Against Rheumatism (EULAR) response criteria [17]. The criterion for disease relapse was current DAS28 $>3.2$ and an increase in DAS28 $>0.6$ compared with baseline. Patients were encouraged to contact investigators if they had a disease relapse between two visits. Patients fulfilling this criterion were classified as relapsers, while patients remaining stable during follow-up were classified as nonrelapsers.

\section{Measurement of clinical disease activity}

All patients underwent clinical assessment at baseline and at 4, 8, and 12 months, including 28-joint swollen and tender joint counts (28-SJC and 28-TJC, respectively), physician and patient global assessment with visual analogue scales $(0-100 \mathrm{~mm})$, ESR $(\mathrm{mm})$, and CRP $(\mathrm{mg} / \mathrm{dL})$. Three composite disease activity indices were subsequently calculated: DAS28-ESR [18], Clinical Disease Activity Index (CDAI) [19], and Simple Disease Activity Index (SDAI) [20].

\section{Serum biomarkers: calprotectin and TNFi trough levels}

Calprotectin serum levels, TNFi trough serum levels, and antidrug antibodies were determined at baseline (visit 0 ) and during disease relapse using an enzyme-linked immunosorbent assay (ELISA) test kit (Calprolab ${ }^{\text {Twt }}$ calprotectin ELISA (ALP), Calpro AS, Oslo, Norway, and Promonitor ${ }^{\circledR}$, Progenika SA, Spain, respectively) according to the manufacturers' protocol as previously described [10]. These ELISA kits are validated and show adequate correlation for the measurement of drug levels and antidrug antibodies [21]. To reduce variations in calprotectin determinations, the whole procedure was performed in a Triturus ${ }^{\circ}$ autoanalyzer. Additionally, serum samples were collected at 4, 8, and 12 months of follow-up to assess longitudinal changes in drug trough serum levels.

\section{Imaging Biomarkers: power Doppler score}

A sonographic assessment was made at baseline (visit 0) using high-sensitivity ultrasound equipment (MyLab
Twice ${ }^{\bullet}$ Esaote, Italy) as previously described [12]. Joint MSUS findings were defined according to published Outcome Measures in Rheumatology (OMERACT) definitions [22]. One experienced sonographer (JR) who was blinded to the results of the clinical joint examination evaluated 11 joints and tendons of each hand (including the proximal interphalangeal joints, metacarpophalangeal joints, and wrists) for synovial hypertrophy ( $\mathrm{SH})$ and intra-articular PD signal according to EULAR guidelines [23]. SH and the PD signals were graded according to the methodology of Szkudlarek et al. [24]. Intra-rater agreement on the MSUS assessment, calculated as previously described [25], was 0.83 for $\mathrm{SH}$ and 0.90 for PD. We made a double ultrasound assessment in the first 10 patients included in the study. The two evaluations were separated by between 24 and $72 \mathrm{~h}$. The same sonographer made both ultrasound explorations and noted the results. This index was calculated as the percentage of agreement between these scores at two time points. The following cut-off values, analogous to kappa coefficients, were defined for intra-rater reliability: $<0.0=$ none, 0 to $0.20=$ poor, 0.21 to $0.40=$ modest, 0.41 to $0.60=$ fair, 0.61 to $0.80=$ good, and 0.81 to $1.00=$ excellent .

By summing the scores for elementary lesions in each joint, we calculated the PD score (range 0-66), the SH score (range 0-66), and the global score (which is the sum of the PD and SH scores; range 0-132). PDUS was defined as a PD signal in synovial tissue [26]. A more-stringent definition of active synovitis (ultrasound-defined active synovitis (UdAS)) developed by our group ( $\mathrm{SH}$ grade $\geq 2$ plus PDUS signal) was also recorded [25].

This study was conducted in accordance with the Declaration of Helsinki and was approved by the Clinical Research Ethics Committee of the Hospital Clínic of Barcelona (Reg. 2013/8382). Signed informed consent was obtained from all patients before study enrolment.

\section{Statistical analysis}

Continuous data are presented as medians and interquartile ranges (IQR) and categorical variables as absolute frequencies and percentages. Relapsers versus nonrelapsers were compared using the Student's $t$ test or Mann-Whitney test when appropriate. The predictive value of calprotectin, TNFi trough serum levels, and PD score for the risk of relapse was assessed using the receiver operating characteristic (ROC), and the most sensitive and specific cut-off was identified; they were then dichotomized, applying an optimal cut-off as per ROC analysis. The predictive values, accuracy, positive likelihood ratio, and maximum Youden index were calculated. The area under the curve (AUC) was estimated using Hanley's corrected confidence intervals (CIs). To illustrate the predictive performance of calprotectin, TNF serum levels, and PD score, Kaplan-Meier curves were constructed from baseline to 
Table 1 Baseline characteristics of patients with disease relapse ("relapsers") or stable disease activity ("nonrelapsers") during 1 year of follow-up

\begin{tabular}{|c|c|c|c|c|}
\hline Characteristic & Total $(n=95)$ & Nonrelapsers $(n=83)$ & Relapsers $(n=12)$ & $p$ value \\
\hline Age (years) & $57(50-66)$ & $57(50-66)$ & $57(48-63.5)$ & 0.614 \\
\hline Female, $n(\%)$ & $61(64.2 \%)$ & $53(63.9 \%)$ & $8(66.7 \%)$ & 1.000 \\
\hline Disease duration (years) & $15(9-21)$ & $15(9-21)$ & $14.5(7.5-24.5)$ & 0.831 \\
\hline Diagnosis, $n(\%)$ & & & & 0.215 \\
\hline Psoriatic arthritis & $51(53,7 \%)$ & $47(56.6 \%)$ & $4(33.3 \%)$ & \\
\hline Rheumatoid arthritis & $44(46.3 \%)$ & $36(43,4 \%)$ & $8(66.7 \%)$ & \\
\hline Time to csDMARD (months) & $25.6(5.1-62.2)$ & $24.4(5.5-62.2)$ & $32.6(5.1-92.3)$ & 0.911 \\
\hline Time to bDMARD (months) & $98.5(36.9-165.9)$ & $98.5(38.8-160.9)$ & $95.9(33.6225 .9)$ & 0.823 \\
\hline Time-to-remission/LDA (months) & $3.27(2.13-4.3)$ & $3.07(1.9-3.97)$ & $20.4(16.8-24.3)$ & $<0.001$ \\
\hline Time-in-remission/LDA (months) & $58.7(26.7-86.6)$ & $60.1(27.6-88.0)$ & $25.0(9.4-59.3)$ & 0.027 \\
\hline Calprotectin $(\mu \mathrm{g} / \mathrm{mL})$ & $1.66(0.69-2.68)$ & $1.44(0.62-2.34)$ & $6.01(5.01-6.44)$ & $<0.001$ \\
\hline CRP (mg/dL) & $0.10(0.04-0.26)$ & $0.09(0.03-0.22)$ & $0.17(0.04-0.52)$ & 0.388 \\
\hline ESR (mm) & $10(7-18)$ & $10(7-16)$ & $14.5(8-21.5)$ & 0.225 \\
\hline Albumin (g/L) & $42(31-48)$ & $43(31-48)$ & $31(31-47)$ & 0.210 \\
\hline Biologic treatment, $n$ (\%) & & & & 0.843 \\
\hline Adalimumab & $34(35.8 \%)$ & $30(36.1 \%)$ & $4(33.3 \%)$ & \\
\hline Etanercept & $44(46.3 \%)$ & $39(47.0 \%)$ & $5(41.7 \%)$ & \\
\hline Infliximab & $17(17.9 \%)$ & $14(16.9 \%)$ & $3(25.0 \%)$ & \\
\hline Biological treatment duration (months) & $61.6(30.8-91.4)$ & $63.2(31.8-92.7)$ & $39.9(25.1-61.2)$ & 0.136 \\
\hline Reduced dose of biologics ${ }^{a}, n(\%)$ & $45(47.4 \%)$ & $40(48.2 \%)$ & $5(41.7 \%)$ & 0.672 \\
\hline Monotherapy, n (\%) & $45(47.4 \%)$ & $42(50.6 \%)$ & $3(25.0 \%)$ & 0.127 \\
\hline Concomitant steroids, $n$ (\%) & $18(18.9 \%)$ & $13(15.7 \%)$ & $5(41.7 \%)$ & 0.047 \\
\hline Global TNFi trough serum levels ( $\mathrm{g} / \mathrm{mL})$ & $2.20(1.07-6.26)$ & $2.70(1.18-6.83)$ & $1.14(0.73-1.52)$ & 0.001 \\
\hline Adalimumab ( $\mu \mathrm{g} / \mathrm{mL})$ & $7.04(2.69-9.40)$ & 7.19 (5.78-9.88) & $1.28(0.73-1.59)$ & 0.009 \\
\hline Etanercept ( $\mu \mathrm{g} / \mathrm{mL})$ & $1.45(1.00-2.25)$ & $1.52(0.92-2.32)$ & $1.24(1.20-1.54)$ & 0.698 \\
\hline Infliximab ( $\mu \mathrm{g} / \mathrm{mL})$ & $2.94(0.86-3.26)$ & $3.16(1.92-4.84)$ & $0(0-1.05)$ & 0.023 \\
\hline DAS28-ESR & $2.03(1.68-2.6)$ & $1.99(1.67-2.52)$ & $2.43(1.89-2.74)$ & 0.145 \\
\hline Remission, $n$ (\%) & $72(75.8 \%)$ & $65(78.3 \%)$ & $7(58.3 \%)$ & 0.175 \\
\hline Low disease activity, n (\%) & $23(24.2 \%)$ & $18(21.7 \%)$ & $5(41.7 \%)$ & 0.127 \\
\hline SDAl & $6.03(2.2-6.26)$ & $6.02(2.11-6.22)$ & $6.18(4.53-6.96)$ & 0.087 \\
\hline CDAl & $6(2-6)$ & $6(2-6)$ & $6(4-6.5)$ & 0.220 \\
\hline Global ultrasound score & $8(3-13)$ & $8(3-13)$ & $17.5(9.5-31)$ & 0.041 \\
\hline PD score & $1(0-2)$ & $1(0-2)$ & $5.5(2.5-10)$ & $<0.001$ \\
\hline SH score & $7(3-11)$ & $6(3-10)$ & $8.5(5-12)$ & 0.210 \\
\hline PDUS, $n$ (\%) & $50(52.6 \%)$ & $38(45.8 \%)$ & $8(66.6 \%)$ & $<0.001$ \\
\hline Number of joints with PDUS & $1(0-2)$ & $1(0-2)$ & $3.5(2.5-5)$ & $<0.001$ \\
\hline UdAS, $n(\%)$ & $29(30.5 \%)$ & $17(20.5 \%)$ & $7(58.3 \%)$ & $<0.001$ \\
\hline
\end{tabular}

Values are shown as median (interquartile range) unless otherwise stated Significant $p$ values are shown in bold typeface

DDMARD biologic disease-modifying antirheumatic drug, CDAl Clinical Disease Activity Index, CRP C-reactive protein, $c s D M A R D$ conventional synthetic diseasemodifying antirheumatic drug, DAS28 28-joint Disease Activity Score, ESR erythrocyte sedimentation rate, LDA low disease activity, PD power Doppler, PDUS power Doppler ultrasound synovitis, SH synovial hypertrophy, SDAI Simplified Disease Activity Index, TNFi tumor necrosis factor inhibitors, UdAS ultrasound-defined active synovitis

${ }^{a}$ Treatment regimen with a lower amount of the drug or longer intervals of administration than those recommended in the package insert for each product 
relapse. Associations between baseline factors and disease relapse were assessed using Cox proportional hazards regression models. Crude odds ratios (ORs) with 95\% CIs were calculated. Multivariate models were constructed to analyze the effect of covariates and to fully adjust the association between calprotectin, TNFi trough serum levels, and PD score with relapse. Models were fitted separately and compared using Akaike Information Criterion (AIC) and the Bayesian Information Criterion (BIC). The generalized estimating equation (GEE) model with an identity link for longitudinal continuous outcomes was used to assess the effect of covariates on TNFi trough serum levels at 0,4 , 8 , and 12 months. The analysis was made using STATA version 11 (STATA Corp., College Station, TX, USA).

\section{Results}

Baseline characteristics

Of the 103 consecutive enrolled patients (47 RA, 56 PsA), eight were lost to follow-up, and 95 patients completed a 1-year follow-up (44 RA, 51 PsA). Table 1 shows the clinical characteristics at baseline. Patients included were mostly women with established disease on prolonged biological treatment: 44 patients were treated with ETN, 34 with ADA, and 17 with IFX, and 45 patients had received a reduced dose of biologics and 45 were on monotherapy. Seventy-two (75.8\%) and 23 patients (24.2\%) fulfilled the DAS28 remission and low disease activity criteria, respectively. Fifty (52.6\%) patients had PDUS, and the median number of joints with PDUS was 1. Twenty-nine (30.5\%) patients fulfilled UdAS criteria.

\section{Baseline serum calprotectin, TNFi trough serum levels, and PDUS, and association with disease relapse}

Eighty-three patients remained in remission/low disease activity over 1 year, and 12 (eight RA, four PsA) relapsed (six patients at 4 months, four at 8 months, and two at 12 months). No differences in disease duration, biological treatment duration, reduced dose, or monotherapy were observed between relapsers and nonrelapsers (Table 1).

Clinically, relapsers had a longer time-to-remission/ low disease activity, shorter time-in-remission/low disease activity, and were more often on steroid treatment compared with nonrelapsers. No differences in time to csDMARD or biological DMARD were observed (Table 1).

At baseline, relapsers had higher calprotectin levels and lower mean TNFi trough serum levels, even when analyzed according to biological agent in the ADA and IFX group. No differences in CRP or ESR were observed (Table 1).

Relapsers showed higher PD activity, with more patients with PDUS, more joints with a PD signal, and a higher global score and PD score than nonrelapsers. In addition, more relapsers fulfilled UdAS criteria. Similar results were obtained when patients were analyzed according to diagnosis (Table 1).

\section{Calprotectin had greater discriminatory capacity to predict relapse than TNFi trough serum levels and the PD score} The cut-off levels determined by ROC analysis for the optimal prediction of relapse for calprotectin, TNFi serum levels, and PD score were $3.7 \mu \mathrm{g} / \mathrm{mL}, 1.61 \mu \mathrm{g} / \mathrm{mL}$, and 4, respectively, and the Youden index was 0.99, 0.51, and 0.64 , respectively. ROC analyses showed that calprotectin (AUC $=1,95 \%$ CI 1.00-1.00) had greater discriminatory capacity than TNFi trough serum levels and PD score in predicting relapse. Table 2 shows further diagnostic statistics of the dichotomized biomarkers. This calprotectin cut-off level had a sensitivity of $100 \%$ and a specificity of $98.8 \%$ for the diagnosis of a relapse (positive likelihood ratio 83 , negative likelihood ratio 0 ).

\section{Predictive performance of calprotectin, TNFi trough serum levels, and PD score for disease relapse}

Kaplan-Meier curves were constructed from baseline to disease relapse to illustrate the predictive performance of calprotectin, TNF serum levels, and PD score. Biomarkers were dichotomized into high versus low according to cut-off levels for optimal prediction of relapse previously calculated by ROC analysis. Survival analyses by log rank tests showed significant differences between groups according to calprotectin serum levels $(p<0.001)$, TNFi trough serum levels $(p=0.004)$, and PD score $(p<0.001)$ (Fig. 1).

Table 2 Diagnostic statistics of dichotomized biomarkers

\begin{tabular}{llll}
\hline & Calprotectin & TNFi trough serum levels & Power Doppler score \\
\hline Cut-off level to predict relapse & $\geq 3.7 \mu \mathrm{g} / \mathrm{mL}$ & $<1.61 \mu \mathrm{g} / \mathrm{mL}$ & $\geq 4$ \\
Area under the curve & $1.000(1.000-1.000)$ & $0.790(0.691-0.889)$ & $0.877(0.772-0.981)$ \\
Sensitivity & $100 \%$ & $68.7 \%$ & $75.0 \%$ \\
Specificity & $98.8 \%$ & $83.3 \%$ & $89.2 \%$ \\
Positive likelihood ratio & 83.0 & 4.12 & 6.92 \\
Negative likelihood ratio & 0.00 & 0.37 & 0.28 \\
Correctly classified & $98.9 \%$ & $70.5 \%$ & $87.4 \%$ \\
Youden index & 0.99 & 0.51 & 0.64 \\
\hline
\end{tabular}

TNFi tumor necrosis factor inhibitors 


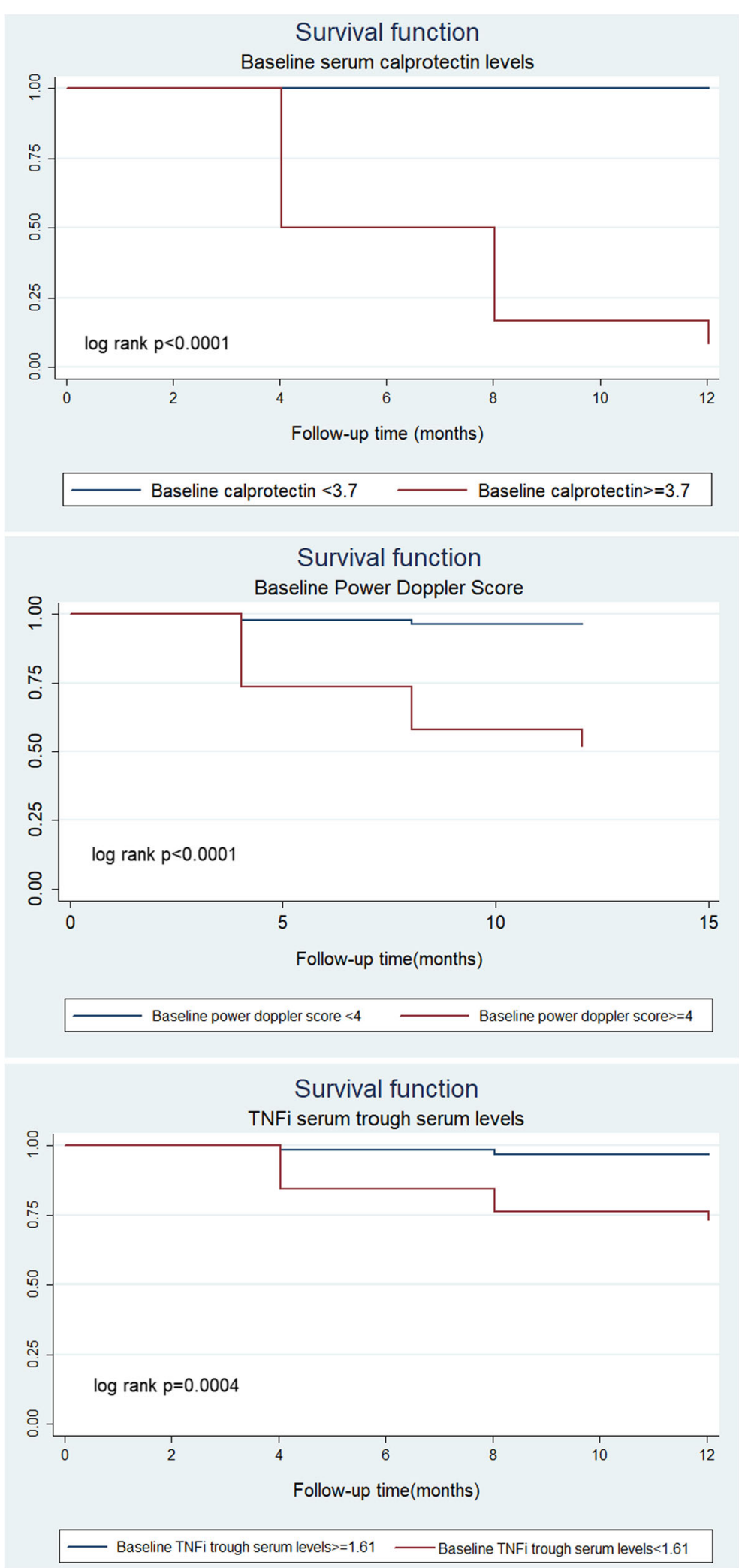

Fig. 1 Kaplan-Meier curves of biomarkers from the time of inclusion to disease relapse. a Calprotectin serum levels. b Power Doppler score. c Tumor necrosis factor inhibitors (TNFi) trough serum levels 


\section{Factors associated with disease relapse}

Univariate Cox regression analyses showed time-to-remission/low disease activity (hazard ratio $(\mathrm{HR})=1.17, p$ $<0.001$ ) was the only clinical variable associated with an increased risk of relapse. In addition, steroid use, calprotectin, TNFi trough serum levels, and PD score were significantly associated with disease relapse. In the multivariate regression, only baseline calprotectin levels were independently associated with disease relapse $(\mathrm{HR}=2.74, p<0.0001)$. No significant interaction terms were detected (Table 3 ).

Calprotectin and TNFi trough serum levels during relapse Serum samples from the 12 relapsers were analyzed during relapse. A significant increase in calprotectin levels was observed in 10 patients, while TNFi trough serum levels decreased in all relapsers compared with baseline values (Fig. 2).

After 1 year, antidrug antibodies were detected in four patients, who all had a relapse (ADA in two out of four relapsers and IFX in two out of three relapsers). All patients with detectable antidrug antibodies had undetectable TNFi trough serum levels.

\section{Longitudinal changes in TNFi trough serum levels}

Multivariate GEE analysis showed that only disease activity by DAS28-ESR was significantly associated with longitudinal changes in TNFi trough serum levels (regression coefficient 0.26 (0.068 to 0.004 ), $p=0.001$ ). This effect was independent of other factors analyzed, such as diagnosis, monotherapy, steroids, and reduced dose of biologics (Table 4).

\section{Discussion}

The results of our study show that TNFi trough serum levels, PD score, and time-to-remission/low disease activity were significantly associated with disease relapse. However, only baseline calprotectin levels independently predicted disease relapse in RA and PsA patients treated with TNFi after a 1-year follow-up.

The innate immune system plays a central role in local inflammation in RA and PsA patients, as demonstrated by the massive infiltration of macrophages into the synovial tissue [27-29]. Most biologics, including TNFi and anti-interleukin (IL)-6, specifically target cytokines related to this cell type, and thus it is not surprising that changes in the number of synovial sublining macrophages correlate with clinical improvement in RA patients [30]. Calprotectin is released by innate immune cells, particularly neutrophils and macrophages, and calprotectin levels provide reliable information about neutrophil activation associated with disease activity in RA and PsA patients [4, 25, 31-33].

In our cohort, calprotectin performed particularly well because all relapsers showed a baseline calprotectin level $>3.7 \mu \mathrm{g} / \mathrm{mL}$; this high accuracy in predicting disease relapses is not completely unexpected. In other inflammatory conditions, such as juvenile idiopathic arthritis (JIA) [13], systemic-onset juvenile idiopathic arthritis (SoJIA) [34], ANCA-associated vasculitis [35], or inflammatory bowel disease (IBD) [36], calprotectin has been shown to be a more sensitive indicator of disease activity and, in consequence, more accurately predicts relapse [34, 37-40].

We have previously demonstrated that RA patients in remission with a PD signal had significantly greater macrophage infiltration in the synovial tissue, comparable

Table 3 Baseline factors associated with disease relapse using Cox proportional hazards regression models

\begin{tabular}{|c|c|c|}
\hline \multirow[t]{2}{*}{ Baseline characteristics } & Univariate & Multivariate \\
\hline & HR (95\% Cl; $p$ value) & HR (95\% Cl; $p$ value) \\
\hline Calprotectin $(\mu \mathrm{g} / \mathrm{mL})$ & $2.38(1.79-3.16 ;<0.0001)$ & $2.74(1.71-4.41 ;<0.0001)$ \\
\hline Power Doppler score, 0-66 & $1.31(1.18-1.45 ;<0.0001)$ & \\
\hline TNFi trough serum levels $(\mu \mathrm{g} / \mathrm{mL})$ & $0.47(0.26-0.88 ; 0.018)$ & $0.36(0.10-1.30 ; 0.120)$ \\
\hline DAS-ESR & $2.10(0.72-6.18 ; 0.175)$ & \\
\hline Time-to-remission (months) & $1.17(1.11-1.23 ;<0.0001)$ & \\
\hline Time-in-remission (months) & $0.98(0.97-1.00 ; 0.087)$ & \\
\hline Female gender & $1.25(0.38-4.15 ; 0.716)$ & \\
\hline Disease duration (months) & $1.02(0.96-1.08 ; 0.510)$ & \\
\hline Diagnosis, RA/PsA & $2.39(0.72-7.93 ; 0.155)$ & $0.80(0.10-6.30 ; 0.832)$ \\
\hline Age (years) & $0.98(0.94-1.03 ; 0.535)$ & \\
\hline Monotherapy & $0.36(0.10-1.33 ; 0.125)$ & $0.51(0.08-3.35 ; 0.484)$ \\
\hline Steroids & $3.12(1.02-10.1 ; 0.046)$ & $0.22(0.04-1.21 ; 0.082)$ \\
\hline
\end{tabular}




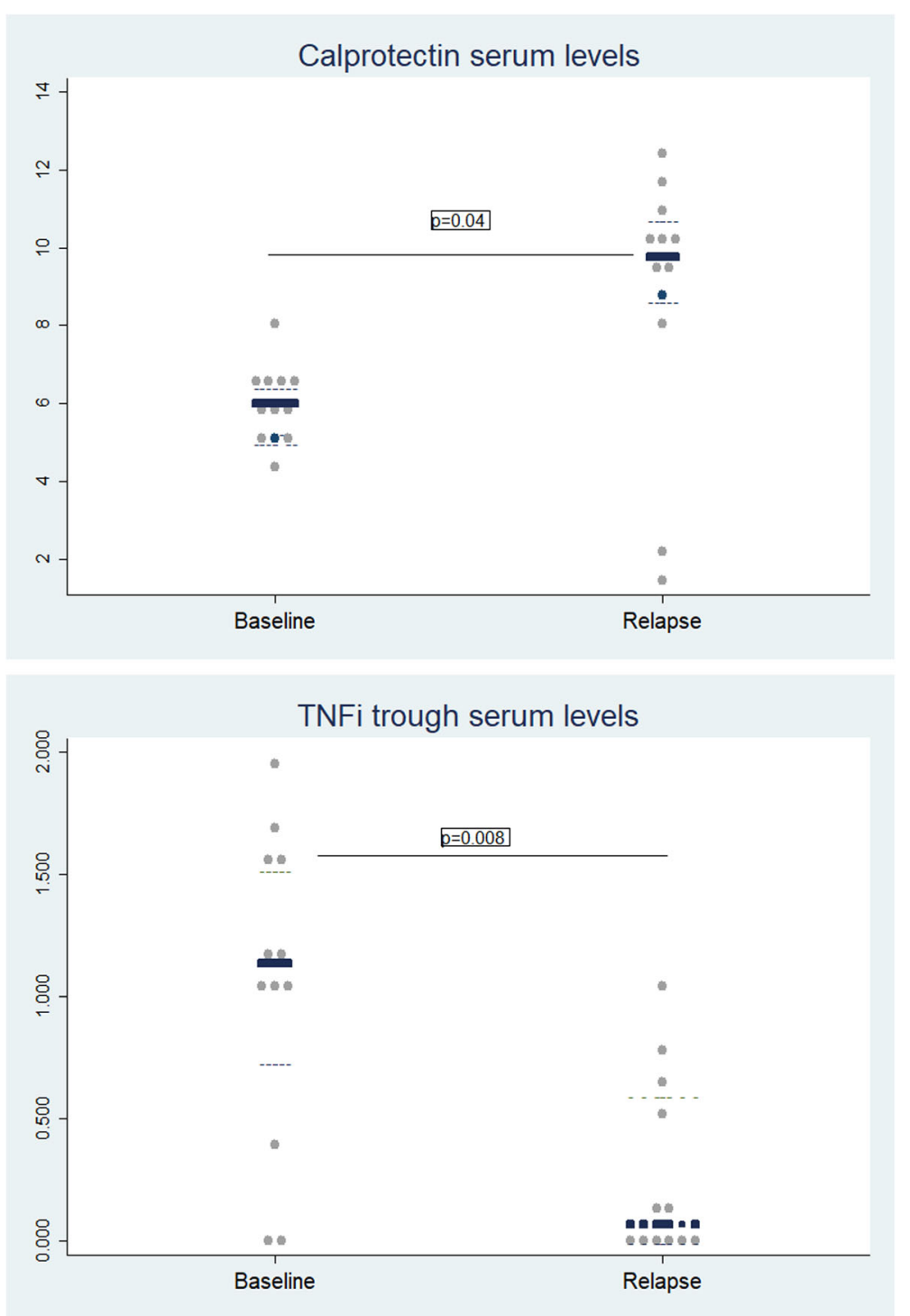

Fig. 2 Biomarkers levels during relapse. a Calprotectin serum levels during relapse. b TNFi trough serum levels during relapse

to clinically active patients [25], which may explain why these patients had threefold higher calprotectin serum levels compared with healthy blood donors [10]. As expected, relapsers showed a significant increase in calprotectin serum levels during the disease relapse, reflecting local ongoing inflammation. Thus, calprotectin serum levels may identify residual inflammatory activity in patients with low disease activity and are a strong predictor of disease relapse.

Nonrelapsers had higher drug trough serum levels than relapsers, even according to the biologic agent, and these significantly decreased during relapse, supporting a previous report on the relationship between inflammation and TNFi pharmacokinetics in RA. In patients with substantial inflammation, IFX serum levels were decreased due to its capture by TNF $\alpha$ [41]. Our results support the emerging role of TNFi trough serum levels as a relevant factor associated with disease activity in RA and PsA patients receiving biological therapy [14-16, 42].

In accordance with previous reports [1], 52.6\% of our patients in clinical remission or with low disease activity (65.9\% RA, 41.1\% PsA) showed PD activity in at least one joint, which has been associated with a higher risk of disease relapse in RA [2,3]. Although there are no data available for polyarticular PsA, logistic regression analyses showed that the PD score, regardless of diagnosis, was associated with relapse, which is a relevant contribution of our study. Remission is not equivalent to the 
Table 4 Factors associated with longitudinal changes in TNFi trough serum levels over 1 year of follow-up using GEE multivariate models

\begin{tabular}{|c|c|c|}
\hline Variable & $\begin{array}{l}\text { TNFi trough serum levels } \\
\beta \text { coefficient }(95 \% \mathrm{Cl})\end{array}$ & $p$ value \\
\hline DAS28-ESR & $0.26(0.068-0.004)$ & 0.001 \\
\hline Reduced dose (yes/no) & $0.022(0.168-0.012)$ & 0.271 \\
\hline Diagnosis (RA/PsA) & $0.005(0.058-0.144)$ & 0.662 \\
\hline Monotherapy (yes/no) & $0.0004(0.090-0.062)$ & 0.863 \\
\hline \multicolumn{3}{|l|}{ Follow-up } \\
\hline Baseline & 1 & \\
\hline 4-month visit & $0.012(0.044-0.0004)$ & 0.023 \\
\hline 8-month visit & $0.004(0.032-0.002)$ & 0.280 \\
\hline 12-month visit & $0.002(0.005-0.032)$ & 0.409 \\
\hline Steroids & $0.020(0.325-0.090)$ & 0.538 \\
\hline Constant & 4.45 (2.99 to 6.25$)$ & $<0.0001$ \\
\hline
\end{tabular}

Significant values are shown in bold typeface

Cl confidence interval, DAS28-ESR 28-joint Disease Activity Score-erythrocyte sedimentation rate, GEE generalized estimating equation, $P S A$ psoriatic arthritis, $R A$ rheumatoid arthritis, TNFi tumor necrosis factor inhibitors

absence of inflammation. Persistence of the PD signal could explain the radiographic damage progression observed in RA and PsA patients in clinical remission $[1,43]$.

As in previous reports, the only clinical factor associated with relapse identified in our study was time-to-remission/ low disease activity. Sustained remission was only determined by time-to-remission in a cohort of early RA patients; the probability of sustained remission increased significantly with decreasing time-to-remission, independently of the DMARD type or strategy [44].

Accurately predicting relapses could avoid delays and related costs [45]. Calprotectin [46] and TNFi trough levels [47] have been included in guidelines on monitoring the therapeutic response in IBD patients. In RA, there are some proposals for decision algorithms which have included calprotectin [48] and TNFi trough levels [49].

The small sample size and low percentage of relapsing patients $(12.6 \%)$ could be a limitation. However, we were able to detect statically significant differences between relapsers and nonrelapsers, which is a strength of our study. We presumed that the use of DAS $28 \leq 3.2$ as the inclusion criteria could limit the interpretation of our results, since this composite index allows residual tender and/or swollen joints in patients classified as being in remission. However, it is the most widely used composite articular index, and therefore our results would be clinically applicable, contributing to the strengths of this study. Although developed to assess disease activity in RA, studies support the use of DAS28 in PsA patients receiving biological therapy [50]. A single rheumatologist performed the US assessment in both hands, and therefore inter-observer reliability could not be calculated, and there is a known significant variability between observers in the assessment of synovitis using US. Also, US assessment focused on the hand could be insufficient to capture inflammatory activity of systemic diseases, such as RA and PsA. However, US examination of hands only could be sufficient to detect $>90 \%$ of RA patients in the clinic with subclinical inflammation [51].

Considering these limitations, we have demonstrated a high accuracy of baseline calprotectin serum levels in predicting relapse in patients with low levels of disease activity.

\section{Conclusions}

In RA and PsA patients with low levels of disease activity, time-to-remission/low disease activity, calprotectin serum levels, TNFi trough serum levels, and PD score were significantly associated with disease relapse. However, only baseline calprotectin levels were independently associated with disease relapse. Calprotectin may be used to stratify disease activity more accurately in patients with low disease activity, guiding therapeutic decisions towards safer and more cost-effective strategies.

\section{Abbreviations}

ACR: American College of Rheumatology; ADA: Adalimumab; AIC: Akaike Information Criterion; AUC: Area under the curve; BIC: Bayesian Information Criterion; CASPAR: Classification of Psoriatic Arthritis; CDAl: Clinical Disease Activity Index; Cl: Confidence interval; CRP: C-reactive protein; CSDMARD: Conventional synthetic disease-modifying antirheumatic drug; DAS28: 28-Joint Disease Activity Score; ESR: Erythrocyte sedimentation rate; ETN: Etanercept; EULAR: European League Against Rheumatism;

GEE: Generalized estimating equation; HR: Hazard ratio; IFX: Infliximab; MSUS: Musculoskeletal ultrasound; OMERACT: Outcome Measures in Rheumatology; OR: Odds ratio; PD: Power Doppler; PDUS: Power Doppler ultrasound synovitis; PsA: Psoriatic arthritis; RA: Rheumatoid arthritis; ROC: Receiver operating characteristic; SDAl: Simple Disease Activity Index; SH: Synovial hypertrophy; TNFi: Tumor necrosis factor inhibitors; UdAS: Ultrasound-defined active synovitis

\section{Acknowledgements}

The authors acknowledge the statistical assistance provided by Dr. Loreto Carmona and Dr. María Jesús García de Yébenes y Prous, the technical advice of David Buss, and the Spanish Rheumatology Society.

\section{Funding}

This study was financially supported by research grants from the Hospital Clinic of Barcelona "Emili Letang 2013", Investigator Initiated Research (IIR) from Pfizer (WS2392358), and the Catalan Society of Rheumatology.

\section{Availability of data and materials}

The datasets used and/or analyzed during the current study are available from the corresponding author on reasonable request.

\section{Authors' contributions}

All authors were involved in drafting the article or revising it critically for important intellectual content, and all authors approved the final version to be published. Study conception and design: RS, JI-M, JR, and JY. Acquisition of data: RS, JI-M, JR, MVH, SRC-V, and VR-E. Analysis and interpretation of data: RS, JI-M, JR, VR-E, JDC, MP, SRC-V, and MVH.

\section{Ethics approval and consent to participate}

This study was conducted in accordance with the Declaration of Helsinki and was approved by the Hospital Clínic of Barcelona Clinical Research Ethics Committee (Reg. 2013/8382). Signed informed consent was obtained from all patients before study enrolment. 


\section{Consent for publication}

Not applicable.

\section{Competing interests}

The authors declare that they have no competing interests.

\section{Publisher's Note}

Springer Nature remains neutral with regard to jurisdictional claims in published maps and institutional affiliations.

\section{Author details}

'Department of Rheumatology, Hospital Clinic, University of Barcelona, Carrer Villarroel 170, 08036 Barcelona, Spain. ${ }^{2}$ Department of Immunology, Hospital Clinic, University of Barcelona, Barcelona, Spain.

Received: 5 June 2018 Accepted: 8 November 2018

Published online: 13 December 2018

\section{References}

1. Brown AK, Quinn MA, Karim Z, Conaghan PG, Peterfy CG, Hensor E, et al. Presence of significant synovitis in rheumatoid arthritis patients with disease-modifying antirheumatic drug-induced clinical remission: evidence from an imaging study may explain structural progression. Arthritis Rheum. 2006:54:3761-73.

2. Scirè CA, Montecucco C, Codullo V, Epis O, Todoerti M, Caporali R. Ultrasonographic evaluation of joint involvement in early rheumatoid arthritis in clinical remission: power Doppler signal predicts short-term relapse. Rheumatology. 2009:48:1092-7.

3. Saleem B, Brown AK, Quinn M, Karim Z, Hensor EM, Conaghan P, et al. Can flare be predicted in DMARD treated RA patients in remission, and is it important? A cohort study. Ann Rheum Dis. 2012;71:1316-21.

4. Berntzen HB, Munthe E, Fagerhol MK. A longitudinal study of the leukocyte protein L1 as an indicator of disease activity in patients with rheumatoid arthritis. J Rheumatol. 1989;16:1416-20.

5. Hansson C, Eriksson C, Alenius G-M. S-calprotectin (S100A8/S100A9): a potential marker of inflammation in patients with psoriatic arthritis. J Immunol Res. 2014:2014:696415.

6. Hammer HB, Odegard S, Fagerhol MK, Landewé R, van der Heijde D, Uhlig $\mathrm{T}$, et al. Calprotectin (a major leucocyte protein) is strongly and independently correlated with joint inflammation and damage in rheumatoid arthritis. Ann Rheum Dis. 2007;66:1093-7.

7. Hammer HB, Ødegård S, Syversen SW, Landewé R, van der Heijde D, Uhlig $\mathrm{T}$, et al. Calprotectin (a major S100 leucocyte protein) predicts 10-year radiographic progression in patients with rheumatoid arthritis. Ann Rheum Dis. 2010;69:150-4.

8. Choi IY, Gerlag DM, Herenius MJ, Thurlings RM, Wijbrandts CA, Foell D, et al. MRP8/14 serum levels as a strong predictor of response to biological treatments in patients with rheumatoid arthritis. Ann Rheum Dis. 2015;74: 499-505.

9. Ademowo OS, Hernandez B, Collins E, Rooney C, Fearon U, van Kuijk AW, et al. Discovery and confirmation of a protein biomarker panel with potential to predict response to biological therapy in psoriatic arthritis. Ann Rheum Dis. 2016;75:234-41.

10. Inciarte-Mundo J, Victoria Hernández M, Ruiz-Esquide V, Raquel CabreraVillalba S, Ramirez J, Cuervo A, et al. Serum calprotectin versus acute-phase reactants in the discrimination of inflammatory disease activity in rheumatoid arthritis patients receiving tumor necrosis factor inhibitors. Arthritis Care Res. 2016;68:899-906.

11. Inciarte-Mundo J, Ruiz-Esquide V, Hernández MV, Cañete JD, Cabrera-Villalba SR, Ramirez J, et al. Calprotectin more accurately discriminates the disease status of rheumatoid arthritis patients receiving tocilizumab than acute phase reactants. Rheumatology. 2015;54:2239-43.

12. Inciarte-Mundo J, Ramirez J, Hernández MV, Ruiz-Esquide V, Cuervo A, Cabrera-Villalba SR, et al. Calprotectin and TNF trough serum levels identify power Doppler ultrasound synovitis in rheumatoid arthritis and psoriatic arthritis patients in remission or with low disease activity. Arthritis Res Ther. 2016;18:160.

13. Gerss J, Roth J, Holzinger D, Ruperto N, Wittkowski H, Frosch M, et al. Phagocyte-specific $\mathrm{S} 100$ proteins and high-sensitivity $\mathrm{C}$ reactive protein as biomarkers for a risk-adapted treatment to maintain remission in juvenile idiopathic arthritis: a comparative study. Ann Rheum Dis. 2012;71:1991-7.
14. Bartelds GM, Krieckaert CL, Nurmohamed MT, van Schouwenburg PA, Lems WF, Twisk JW, et al. Development of antidrug antibodies against adalimumab and association. JAMA Intern Med. 2011;305:1460-8.

15. de Vries MK, Wolbink GJ, Stapel SO, de Vrieze H, van Denderen JC, Dijkmans BA, et al. Decreased clinical response to infliximab in ankylosing spondylitis is correlated with anti-infliximab formation. Ann Rheum Dis. 2007:66:1252-4.

16. Chen DY, Chen YM, Tsai WC, Tseng JC, Chen YH, Hsieh CW, et al. Significant associations of antidrug antibody levels with serum drug trough levels and therapeutic response of adalimumab and etanercept treatment in rheumatoid arthritis. Ann Rheum Dis. 2015:74:e16.

17. Van Gestel AM, Haagsma CJ, Van Riel PLCM. Validation of rheumatoid arthritis improvement criteria that include simplified joint counts. Arthritis Rheum. 1998:41:1845-50.

18. Prevoo ML, van't Hof MA, Kuper HH, van Leeuwen MA, van de Putte LB, van Riel PL. Modified disease activity scores that include twenty-eight-joint counts: development and validation in a prospective longitudinal study of patients with rheumatoid arthritis. Arthritis Rheum. 1995:38:44-8.

19. Aletaha D, Nell V, Stamm T, Uffmann M, Pflugbeil S, Machold K, et al. Acute phase reactants add little to composite disease activity indices for rheumatoid arthritis: validation of a clinical activity score. Arthritis Res Ther 2005;7:R796-806.

20. S Smolen JS, Breedveld FC, Schiff MH, Kalden JR, Emery P, Eberl G, et al. A simplified disease activity index for rheumatoid arthritis for use in clinical practice. Rheumatology. 2003;42:244-57.

21. Valor L, Hernández-Flórez D, de la Torre I, Llinares F, Rosas J, Yagüe J, et al. Agreement in assessment of infliximab and adalimumab levels in rheumatoid arthritis: interlaboratory and interassay comparison. Clin Exp Rheumatol. 2015;33:617-23.

22. Wakefield RJ, Balint PV, Szkudlarek M, Filippucci E, Backhaus M, D'Agostino $M A$, et al. Musculoskeletal ultrasound including definitions for ultrasonographic pathology. J Rheumatol. 2005;32:2485-7.

23. Backhaus M, Burmester GR, Gerber T, Grassi W, Machold KP, Swen WA, et al. Guidelines for musculoskeletal ultrasound in rheumatology. Ann Rheum Dis. 2001;60:641-9.

24. Szkudlarek M, Court-Payen M, Jacobsen S, Klarlund M, Thomsen HS, Østergaard M. Interobserver agreement in ultrasonography of the finger and toe joints in rheumatoid arthritis. Arthritis Rheum. 2003;48:955-62.

25. Ramírez J, Celis R, Usategui A, Ruiz-Esquide V, Faré R, Cuervo A, et al. Immunopathologic characterization of ultrasound-defined synovitis in rheumatoid arthritis patients in clinical remission. Arthritis Res Ther. 2016;18:74.

26. Naredo E, Collado P, Cruz A, Palop MJ, Cabero F, Richi P, et al. Longitudinal power Doppler ultrasonographic assessment of joint inflammatory activity in early rheumatoid arthritis: predictive value in disease activity and radiologic progression. Arthritis Care Res. 2007:57:116-24.

27. Youssef PP, Smeets TJ, Bresnihan B, Cunnane G, Fitzgerald O, Breedveld F, et al. Microscopic measurement of cellular infiltration in the rheumatoid arthritis synovial membrane: a comparison of semiquantitative and quantitative analysis. Br J Rheumatol. 1998;37:1003-7.

28. Taccari E, Fattorossi A, Moretti S, Riccieri V, Fasani M, Zoppini A. Phenotypic profile of major synovial cell populations in longstanding psoriatic arthritis. J Rheumatol. 1987;14:525-30.

29. Veale D, Yanni G, Rogers S, Barnes L, Bresnihan B, Fitzgerald O. Reduced synovial membrane macrophage numbers, ELAM-1 expression, and lining layer hyperplasia in psoriatic arthritis as compared with rheumatoid arthritis. Arthritis Rheum. 1993;36:893-900.

30. Haringman JJ, Gerlag DM, Zwinderman AH, Smeets TJM, Kraan MC, Baeten $D$, et al. Synovial tissue macrophages: a sensitive biomarker for response to treatment in patients with rheumatoid arthritis. Ann Rheum Dis. 2005;64: 834-8.

31. Berntzen $H B$, Munthe $E$, Fagerhol MK. The major leukocyte protein $L 1$ as an indicator of inflammatory joint disease. Scand J Rheumatol. 1988;76:251-6.

32. Brun JG, Jonsson R, Haga HJ. Measurement of plasma calprotectin as an indicator of arthritis and disease activity in patients with inflammatory rheumatic diseases. J Rheumatol. 1994;21:733-8.

33. Brun JG, Haga HJ, Bøe E, Kallay I, Lekven C, Berntzen HB, et al. Calprotectin in patients with rheumatoid arthritis: relation to clinical and laboratory variables of disease activity. J Rheumatol. 1992;19:859-62.

34. Holzinger D, Frosch M, Kastrup A, Prince FHM, Otten MH, Van SuijlekomSmit LW, et al. The Toll-like receptor 4 agonist MRP8/14 protein complex is a sensitive indicator for disease activity and predicts relapses in systemiconset juvenile idiopathic arthritis. Ann Rheum Dis. 2012;71:974-80. 
35. Pepper RJ, Hamour S, Chavele K, Todd SK, Rasmussen N, Flint SM, et al. Leukocyte and serum S100A8/S100A9 expression reflects disease activity in ANCA-associated vasculitis and glomerulonephritis. Kidney Int. 2013;83: 1150-8.

36. Balzola F, Cullen G, Hoentjen F, Ho GT, Russell R. Fecal calprotectin more accurately reflects endoscopic activity of ulcerative colitis than the Lichtiger index, C-reactive protein, platelets, hemoglobin, and blood leukocytes. Inflamm Bowel Dis Monit. 2013;13:159-60.

37. Rothmund F, Gerss J, Ruperto N, Däbritz J, Wittkowski H, Frosch M, et al. Validation of relapse risk biomarkers for routine use in patients with juvenile idiopathic arthritis. Arthritis Care Res. 2014;66:949-55.

38. Schulze zur Wiesch A, Foell D, Frosch M, Vogl T, Sorg C, Roth J. Myeloid related proteins MRP8/MRP14 may predict disease flares in juvenile idiopathic arthritis. Clin Exp Rheumatol. 2016;22:368-73.

39. Pepper RJ, Draibe JB, Caplin B, Fervenza FC, Hoffman GS, Kallenberg CGM, et al. The association of serum calprotectin (S100A8/S100A9) levels with disease relapses in PR3-ANCA-associated vasculitis. Arthritis Rheumatol. 2016; [Epub ahead of print]

40. De Vos M, Louis EJ, Jahnsen J, Vandervoort JGP, Noman M, Dewit O, et al. Consecutive fecal calprotectin measurements to predict relapse in patients with ulcerative colitis receiving infliximab maintenance therapy. Inflamm Bowel Dis. 2013:19:2111-7.

41. Ternant D, Ducourau E, Perdriger A, Corondan A, Le Goff B, DevauchellePensec $V$, et al. Relationship between inflammation and infliximab pharmacokinetics in rheumatoid arthritis. Br J Clin Pharmacol. 2014;78:118-28.

42. Jamnitski A, Krieckaert CL, Nurmohamed MT, Hart MH, Dijkmans BA, Aarden $L$, et al. Patients non-responding to etanercept obtain lower etanercept concentrations compared with responding patients. Ann Rheum Dis. 2012 71:88-91.

43. El Miedany Y, El Gaafary M, Youssef S, Ahmed I, Nasr A. Tailored approach to early psoriatic arthritis patients: clinical and ultrasonographic predictors for structural joint damage. Clin Rheumatol. 2015;34:307-13.

44. Schipper LG, Fransen J, den Broeder A, Van Riel PLCM. Time to achieve remission determines time to be in remission. Arthritis Res Ther. 2010;12:R97.

45. Bartlett SJ, Hewlett S, Bingham CO, Woodworth TG, Alten R, Pohl C, et al. Identifying core domains to assess flare in rheumatoid arthritis: an OMERACT international patient and provider combined Delphi consensus. Ann Rheum Dis. 2012;71:1855-60.

46. Heida A, Dijkstra A, Groen H, Muller Kobold A, Verkade H, van Rheenen P. Comparing the efficacy of a web-assisted calprotectin-based treatment algorithm (IBD-live) with usual practices in teenagers with inflammatory bowel disease: study protocol for a randomized controlled trial. Trials. 2015; $16: 271$.

47. Afif W, Loftus EV Jr, Faubion WA, Kane SV, Bruining DH, Hanson KA, et al. Clinical utility of measuring infliximab and human anti-chimeric antibody concentrations in patients with inflammatory bowel disease. Am J Gastroenterol. 2010;105:1133-9.

48. Nair SC, Welsing PMJ, Choi IYK, Roth J, Holzinger D, Bijlsma JWJ, et al. A personalized approach to biological therapy using prediction of clinical response based on MRP8/14 serum complex levels in rheumatoid arthritis patients. PLoS One. 2016;11:1-12.

49. Garcês S, Antunes M, Benito-Garcia E, da Silva JC, Aarden L, Demengeot J. A preliminary algorithm introducing immunogenicity assessment in the management of patients with RA receiving tumour necrosis factor inhibitor therapies. Ann Rheum Dis. 2014;73:1138-43.

50. Fransen J, Antoni C, Mease PJ, Uter W, Kavanaugh A, Kalden JR, et al. Performance of response criteria for assessing peripheral arthritis in patients with psoriatic arthritis: analysis of data from randomised controlled trials of two tumour necrosis factor inhibitors. Ann Rheum Dis. 2006:65:1373-8.

51. Hammer H, Kvien T, Terslev L. Ultrasound of the hand is sufficient to detect subclinical inflammation in rheumatoid arthritis remission: a post hoc longitudinal study. Arthritis Res Ther. 2017;19:221.

Ready to submit your research? Choose BMC and benefit from:

- fast, convenient online submission

- thorough peer review by experienced researchers in your field

- rapid publication on acceptance

- support for research data, including large and complex data types

- gold Open Access which fosters wider collaboration and increased citations

- maximum visibility for your research: over $100 \mathrm{M}$ website views per year

At BMC, research is always in progress.

Learn more biomedcentral.com/submissions 